\title{
Hand patterns in prostatic cancers
}

\author{
Mohammad Ashraf, ${ }^{1}$ Thomas Mohan, ${ }^{2}$ Edmond Fernandes, ${ }^{3}$ \\ General medicine department,Father Muller Medical College/Rajiv Gandhi university health sciences/, India
}

\section{Introduction}

Prostatic cancers has been showing increasing trend in the elderly age group.We intended to explore if there are hands patterns which play a significant role towards prostate cancer- the most common cancer in the geriatric age group but the present day knowledge of its etiology is limited ( Li et al, 2004). It's a cross sectional study which measures the index and ring finger length in patients with prostate cancer.

Finger length ratio has since been correlated to medical, behavioral and psychological conditions, particularly those influenced by prenatal hormone exposure ( J Solid Tumors, 2012). The ratio of the lengths of the index (2D) and ring (4D) fingers has been suggested as a proxy indicator of prenatal androgen activity, with low 2D : 4D reflecting higher in utero testosterone exposure (Manning et al, 1998; McIntyre, 2006; Ho“nekopp and Watson, 2010). There are several lines of evidence indicating that $2 \mathrm{D}: 4 \mathrm{D}$ is affected by prenatal androgens (Breedlove, 2010), and that digit ratios are longitudinally stable (McIntyre et al, 2005; Trivers et al, 2006).

Hormone exposure in early life has been implicated in the etiology of numerous cancers (Potischman et al, 2005). Prostate cancer is a hormonally driven and a regulated disease, but studies have failed to detect associations between a single measure of hormone levels in adulthood and prostate cancer risk (Roddam et al, 2008). Two recent studies have aimed to assess whether 2D : 4D is associated with prostate cancer (Jung et al, 2011; Rahman et al, 2011). Both of these studies concluded that low 2D : 4D, and thereby high prenatal testosterone, is a marker of increased risk of prostate cancer. Prostate cancer is more common in Western men, and incidence is rising rapidly in most countries, including low-risk populations (Ferlay \& Forman 2008). Highest incidence rates for prostate cancer are reported from US, Detroit, Black (AAR = 141.5 per 105$)$ while in the Asian subcontinent, the rates are highest in Japan, Hiroshima (AAR = 10.9 per 105) (Parkin \& Thomas 2002). In India, the age-standardized rates (per 105 ) vary between Delhi (11.5), Mumbai (6.3), Chennai (5.2), Bangalore (6.0) and Barshi (1.6) (Nandakumar, 2006). Prostate cancer (PCA) is the most common cancer in men and the commonest overall, with a reported incidence of 165.8 per 100.000 ( Edward et al, 2006). Although its exact etiology is currently unknown, it has been correlated to factors such as age, race, familial history and hormone exposure ( Hsing, Chokkalingam, 2010).

\section{Materials and Methods:}

A sample size of 27 patients between 50 and 80 years were included this study all subjects who were diagnosed by clinical and histological analysis were currently under treatment follow-up. They were subjected to measurement of their index and ring finger after being clearly told of what we intended to do. The length of the index finger was divided by the length of the ring finger to obtain $2 \mathrm{D}: 4 \mathrm{D}$ ratio which was then divided into three groups $2 \mathrm{D}>4 \mathrm{D}, 2 \mathrm{D}<4 \mathrm{D}, 2 \mathrm{D}=4 \mathrm{D}$ and the data was analyzed for obtaining results.

\section{Results:}

The mean length of the Index (2D) finger to Ring finger (4D) in the Right hand of 27 patients suffering from prostatic cancer was 10.03 to $10.54(\mathrm{cms}) \quad(\mathrm{t}=2.596, \mathrm{p}=.012 \mathrm{sig})$ respectively with mean age of $67.07 \pm$ 5.75 and it was 9.51 to $9.80(\mathrm{cms})(\mathrm{t}=1.284, \mathrm{p}=0.205 \mathrm{~ns})$ for the 27 controls with a mean age of $70.92 \pm 7.3$.

In the right hand the $2 \mathrm{D}<4 \mathrm{D}$ or lower $2 \mathrm{D}$ :4D ratio or values below 1 had 20 patients $(74.1 \%)$ having prostate cancer and their reading where significant with an OR 1.96, 95\% CI $0.62-6.22$ indicating the risk pattern of having a lower ratio or $2 \mathrm{D}<4 \mathrm{D}$ or longer ring finger (4D) than the index finger (2D). The same ratio $2 \mathrm{D}<4 \mathrm{D}$ indicated a higher OR $2.55,95 \%$ CI $0.84-7.84$ for the left hand in these patients.

In the right hand the 2D > 4D or higher 2D:4D ratio or values above 1 had 3 patients $(11.1 \%)$ gave OR $0.55,95 \%$ CI $0.19-2.56$, while the left finger gave an OR $0.68,95 \%$ CI $0.19-2.31$, both the values are indicative of the protective function of having a longer index (2D) finger than the ring (4D) finger or $2 \mathrm{D}>4 \mathrm{D}$ or higher 2D:4D which is greater than 1 . 


\section{Right hand values :}

\begin{tabular}{|cc|c|c|c|c|}
\hline RIGHT HAND & Finger & $\mathrm{N}$ & Mean & Std. Deviation & $\mathrm{T}$ \\
\hline GROUP & Index(2D) & 27 & 10.0370 & .695 & 2.596 \\
PROSTATE CANCER & 27 & 10.5444 & .740 & $\mathrm{p}=.012 \mathrm{sig}$ \\
\hline Ring(4D) & Index(2D) & 27 & 9.5111 & .827 & 1.284 \\
& Ring(4D) & 27 & 9.8000 & .809 & $\mathrm{p}=.205 \mathrm{~ns}$ \\
\hline
\end{tabular}

\begin{tabular}{|c|c|c|c|c|c|}
\hline \multicolumn{6}{|l|}{ RIGHT HAND } \\
\hline $\begin{array}{c}\text { FINGER/GRO } \\
\text { UPS }\end{array}$ & $\begin{array}{c}\text { PROSTATE } \\
\text { CANCER }\end{array}$ & CONTROLS & Total & ODDS RATIO & $\begin{array}{c}\text { CONFIDENCE } \\
\text { INTERVALS } \\
95 \%\end{array}$ \\
\hline $2 \mathrm{D}<4 \mathrm{D}$ & $\begin{array}{c}20 \\
74.1 \%\end{array}$ & $\begin{array}{c}16 \\
59.3 \%\end{array}$ & $\begin{array}{c}36 \\
66.7 \%\end{array}$ & 1.96 & $0.62-6.22$ \\
\hline $2 \mathrm{D}=4 \mathrm{D}$ & $\begin{array}{c}4 \\
14.8 \%\end{array}$ & $\begin{array}{c}6 \\
22.2 \%\end{array}$ & $\begin{array}{c}10 \\
18.5 \%\end{array}$ & 0.61 & $0.15-2.46$ \\
\hline $2 \mathrm{D}>4 \mathrm{D}$ & $\begin{array}{c}3 \\
11.1 \%\end{array}$ & $\begin{array}{c}5 \\
18.5 \%\end{array}$ & $\begin{array}{c}8 \\
14.8 \%\end{array}$ & 0.55 & $0.19-2.56$ \\
\hline $\begin{array}{c}\text { Total } \\
\text { Count } \%\end{array}$ & $\begin{array}{c}27 \\
100.0 \%\end{array}$ & $\begin{array}{c}27 \\
100.00 \%\end{array}$ & $\begin{array}{c}54 \\
100.0 \%\end{array}$ & & \\
\hline
\end{tabular}

\section{LEFT HAND VALUES:}

\begin{tabular}{|cc|c|c|c|c|}
\hline \multicolumn{1}{|l|}{ LEFT HAND } & Finger & $\mathrm{N}$ & MEAN & $\begin{array}{c}\text { STANDARD } \\
\text { DEVIATION }\end{array}$ & $\mathrm{T}$ \\
\hline \multirow{2}{*}{ GROUP } & Index & 27 & 10.1000 & .88492 & 1.205 \\
& Ring & 27 & 10.3667 & .73485 & $\mathrm{p}=.234 \mathrm{~ns}$ \\
\hline CONTROLS & Index & 27 & 9.6259 & .99406 & .688 \\
& Ring & 27 & 9.8000 & .83857 & $\mathrm{p}=.495 \mathrm{~ns}$ \\
\hline
\end{tabular}

\begin{tabular}{|c|c|c|c|c|c|}
\hline LEFT HAND & & & & & \\
\hline $\begin{array}{l}\text { FINGER/ } \\
\text { GROUPS }\end{array}$ & $\begin{array}{l}\text { PROSTATE } \\
\text { CANCER }\end{array}$ & CONTROLS & Total & $\begin{array}{l}\text { ODDS } \\
\text { RATIO }\end{array}$ & $\begin{array}{l}\text { CONFIDENCE } \\
\text { INTERAVAL 95\% }\end{array}$ \\
\hline $2 \mathrm{D}<4 \mathrm{D}$ & $\begin{array}{c}19 \\
70.4 \%\end{array}$ & $\begin{array}{c}13 \\
48.1 \%\end{array}$ & $\begin{array}{c}32 \\
59.3 \%\end{array}$ & 2.55 & $0.84-7.84$ \\
\hline $2 \mathrm{D}=4 \mathrm{D}$ & $\begin{array}{c}2 \\
7.4 \%\end{array}$ & $\begin{array}{c}6 \\
22.2 \%\end{array}$ & $\begin{array}{c}8 \\
14.8 \%\end{array}$ & 0.280 & $0.05-1.54$ \\
\hline $2 \mathrm{D}>4 \mathrm{D}$ & $\begin{array}{c}6 \\
22.2 \%\end{array}$ & $\begin{array}{c}8 \\
29.6 \%\end{array}$ & $\begin{array}{c}14 \\
25.9 \%\end{array}$ & 0.680 & $0.19-2.31$ \\
\hline $\begin{array}{c}\text { TOTAL } \\
\text { COUNT\% }\end{array}$ & $\begin{array}{c}27 \\
100.0 \%\end{array}$ & $\begin{array}{c}27 \\
100.0 \%\end{array}$ & $\begin{array}{c}54 \\
100.0 \%\end{array}$ & & \\
\hline
\end{tabular}

$2 \mathrm{D}<4 \mathrm{D}=$ ratio below 1 or index shorter than ring

$2 \mathrm{D}=4 \mathrm{D}=$ ratio equal to 1 or index equal to ring

$2 \mathrm{D}>4 \mathrm{D}=$ ratio above 1 or index greater than ring

\section{Discussion:}

Two recent studies have examined whether 2D : 4D is associated with prostate cancer risk. The first was a clinical cohort study of 366 Korean men presenting with lower urinary tract symptoms (Jung et al, 2011). This study found that the odds of being diagnosed with prostate cancer were significantly higher for men with low 2D : 4D compared with high 2D : 4D (OR 3.22, 95\% CI, 1.33-7.78). The second was a large case-control 
study, which reported an inverse association between self-assessed right $2 \mathrm{D}: 4 \mathrm{D}$ and odds of prostate cancer (OR for index finger longer than ring finger vs index finger shorter than ring finger $0.67,95 \% \mathrm{CI}, 0.57-0.80$ ) (Rahman et al, 2011). This study also reported a remarkably strong association between $2 \mathrm{D}: 4 \mathrm{D}$ and prostate cancer diagnosed before the age of 60 years (OR $0.13,95 \%$ CI, $0.09-0.21$ ).

We cannot exclude the possibility that high $2 \mathrm{D}: 4 \mathrm{D}$ is associated with lower risk of early onset prostate cancer. High 2D : 4D is a marker of low in utero testosterone exposure, and thus hormone activity, early in development, might impact upon later risk of prostate cancer. Further research is required to clarify any association between 2D : 4D and prostate cancer, especially for younger men under 60 years in India.

\section{Conclusion:}

The mean of ring finger being taller than index finger in patients with prostatic lesion allows us to infer that, there could be a possibility of exploring the digits length which will invariably add to the etiological factor of research in prostate cancer and a need for a larger multi centric study may concretize the etiological finding and necessary education \& prevention can be met in an Indian context. Hand pattern might represent a simple marker for prostate cancer risk, particularly in men age above 60 years. Further research is required to clarify any association between 2D : 4D and prostate cancer, especially for younger men under 60 years.

\section{Acknowledgement:}

The authors place on record to thank Mr. Kotian and Sucharithra Suresh for their statistical analysis and comments. We also thank our institute for facilitating the smooth carrying on this research.

\section{Conflict of Interest:}

We declare hereby that there is no conflict of interest and there is no industry or sponsor for this paper.

\section{References:}

[1]. Ferlay J, Shin HR, Bray F, Forman D, Mathers C, Parkin DM. Estimates of worldwide burden of cancer in 2008: GLOBOCAN 2008. Int J Cancer. 2010 Dec 15;127(12):2893-917

[2]. Parkin, DM, Whelan SL, Ferlay J, Teppo L, Thomas DB. Cancer Incidence in Five Continents. Vol. 8. Lyon, IARC: IARC Scientific Publications No. 155; 2002.

[3]. Nandakumar A. Consolidated Report of the Population Based Cancer Registries 2001-04. India: National Cancer Registry Programme, Indian Council of Medical Research; 2006.

[4]. Li H, Stampfer MJ, Giovannucci EL, Morris JS, Willett WC, Gaziano JM, Ma J. A prospective study of plasma selenium levels and prostate cancer risk. J Natl Cancer Inst. 2004 May 5;96(9):696-703.

[5]. Hopp Renato Nicolás, Jorge Jacks (2012) Right hand digit ratio (2D:4D) is associated with prostate cancer: Findings of an admixed population study. J Solid Tumors, February 2012, Vol. 2, No. 1

[6]. Edwards BK, Ward E, Kohler BA, Eheman C, Zauber AG, Anderson RN, Jemal A, Schymura MJ, Lansdorp-Vogelaar I, Seeff LC, van Ballegooijen M, Goede SL, Ries LA. Annual report to the nation on the status of cancer, 1975-2006, featuring colorectal cancer trends and impact of interventions (risk factors, screening, and treatment) to reduce future rates. Cancer. $2010 \mathrm{Feb} 1 ; 116(3) 544-73$

[7]. Hsing AW, Chokkalingam AP. Prostate cancer epidemiology. Front Biosci. 2006;11:1388-413. Pmid:16368524 http://dx.doi.org/10.2741/1891

[8]. Ho"nekopp J, Watson S (2010) Meta-analysis of digit ratio 2D : 4D shows greater sex difference in the right hand. Am J Hum Biol 22: 619- 630

[9]. Breedlove SM (2010) Minireview: organizational hypothesis: instances of the fingerpost. Endocrinology 151: 4116-4122

[10]. McIntyre MH, Ellison PT, Lieberman DE, Demerath E, Towne B (2005) The development of sex differences in digital formula from infancy in the FELS Longitudinal Study. Proc Biol Sci 272: 1473-1479

[11]. Potischman N, Troisi R, Thadhani R, Hoover RN, Dodd K, Davis WW, Sluss PM, Hsieh CC, Ballard-Barbash R. Pregnancy hormone concentrations across ethnic groups: implications for later cancer risk. Cancer Epidemiol Biomarkers Prev. 2005 Jun;14(6):1514-20.

[12]. Jung H, Kim KH, Yoon SJ, Kim TB. Second to fourth digit ratio: a predictor of prostate-specific antigen level and the presence of prostate cancer. BJU Int.2011 Feb;107(4):591-6.

[13]. Rahman AA, Lophatananon A, Stewart-Brown S, Harriss D, Anderson J, Parker T, Easton D, Kote-Jarai Z, Pocock R, Dearnaley D, Guy M, O'Brien L, Wilkinson RA, Hall AL, Sawyer E, Page E, Liu JF; UK Genetic Prostate Cancer Study Collaborators; British Association of Urological Surgeons' Section of Oncology, Eeles RA, Muir K. Hand pattern indicates prostate cancer risk. Br J Cancer. 2011 Jan 4;104(1):175-7.

[14]. Endogenous Hormones and Prostate Cancer Collaborative Group, Roddam AW, Allen NE, Appleby P, Key TJ. Endogenous sex hormones and prostate cancer: a collaborative analysis of 18 prospective studies. J Natl Cancer Inst. 2008 Feb 6;100(3):170-83. 